\title{
Influence of hierarchical porosity on the mechanical properties of porous woven composites under thermomechanical loading
}

\author{
Zhengmao Yang ${ }^{\mathrm{a}, *}$, Han Yan ${ }^{\mathrm{b}}$, Guian Qian ${ }^{\mathrm{a}, \mathrm{c}, *}$, Zhongdong Ji ${ }^{\mathrm{a}}$ \\ anstitute of Mechanics, Chinese Academy of Sciences, 100190 Beijing, China \\ ${ }^{\mathrm{b}}$ School of Aerospace Engineering, Tsinghua University, 100084 Beijing, China \\ c School of Engineering Science, University of Chinese Academy of Sciences, 100049 Beijing, China
}

\section{A R T I C L E I N F O}

Article history:

Received 24 February 2020

Received in revised form 23 April 2020

Accepted 4 May 2020

Available online 16 May 2020

\section{Keywords:}

Porous woven composites

Hierarchical porosity

Micromechanics

Continuum damage mechanics

Thermomechanical behaviors

\begin{abstract}
A B S T R A C T
The manufacturing process often results in hierarchical microstructures of porous woven composites, with pores and cracks in the matrix and fibers ranging from nanometers to hundreds of micrometers. This research is devoted to the mechanical behavior of porous woven composites with hierarchical pores of very different sizes under thermomechanical loading. A micromechanics-based damage model is developed within the continuum damage mechanics (CDM) considering the contribution of hierarchical pores for capturing the thermomechanical behaviour of porous woven composites. The predicted results of the proposed model are compared with available experimental results as well as other analytical methods to verify its correctness. The main advantages of the proposed model, comparing to the existing counterparts, are that the contributions of hierarchical pores can be examined on the material macroscopic mechanical responses, and the capability in characterizing the damage behaviour of matrix and fibers. This work can provide theoretical guidance for controlling the formation of hierarchical porosity during the manufacturing process.
\end{abstract}

(c) 2020 Elsevier Ltd. All rights reserved.

\section{Introduction}

Porous woven composites, are extensively applied in many structural components in aircraft and other industries attributing to excellent durability, high strength, high stiffness to weight ratio, low density and design flexibility. Thus, to understand and to predict the mechanical properties of porous woven composites is critical (Vincent et al., 2009; Chateau et al., 2014). Besides, experimental studies, as well as observation, have shown that there are hierarchical pores of rather different sizes in the porous woven composites due to the manufacturing process, and the change of hierarchical porosity during loading significantly affects the mechanical properties of the composites (Rajan and Zok, 2014; Liebig et al., 2016). In particular, when the composites are suffering thermomechanical loading, the thermal stress of the materials results in the hierarchical pores growth, until the pores coalesce to form a macro-crack leading to the failure of the materials (Bale et al., 2013). The expansion or combination of pores may exist in the fiber architecture, matrix and even interfacial regions, which has a significant impact on the mechanical property of com-

\footnotetext{
* Corresponding author.

E-mail addresses: zmyang@imech.ac.cn (Z. Yang), qianguian@imech.ac.cn (G. Qian).
}

posites and may lead to the fiber misalignment, matrix voids and delamination, etc. The questions addressed in this work are establishing a quantitative relationship between the effective properties and the porosity of porous woven composites under thermomechanical loading considering the hierarchical porosity, and understanding the influence of hierarchical porosity on the thermomechanical damage in the matrix and fibers of porous woven composites.

Hierarchical pores, also known as hierarchical porosity, can be defined as the third component in porous woven composites (Sevostianov, 2009; Vural and Ravichandran, 2003). Evidently, the porosity is a fundamental microstructural quantity that strongly controls the physical properties of the material such as strength, stiffness, conductivity, diffusivity and permeability (Ma et al., 2014; Patel et al., 2019). To date, a lot of research has focused on the effect of porosity on the mechanical properties of composites, and several analytical models have been proposed to predict the elastic properties in the presence of pores (Rajan and Zok, 2012), which extended traditional inclusion theories. Huang and Talreja (2005) considered the geometry of voids in the unidirectional composites in the elastic property predication model, and compared the results with finite element analysis and the MoriTanaka theory, which showed that the voids have a great influence on the out-of-plane modulus of the material, but small influence 
on the in-plane properties; Xia et al. (2009) and Xia et al. (2011) proposed a method to predict the effective elastic properties of nanoporous materials taking into account the hierarchical structures, and the uniaxial microtensile tests were conducted to analyze the mechanical behaviour of the nanoporous materials. Sun et al. (2013) established the scaling laws for nanoporous metals to predict the mechanical properties in terms of the porosity. Timothy and Meschke (2016) estimated the elastic properties of porous materials by the principle of recurrence and mean-field Eshelby homogenization scheme, and proposed an explicit model allowing for a simple computational implementation. Choi et al. (2018) proposed an expanded unmixing-mixing model incorporating micro-state correction factors to predict the material properties of porous woven composites, and the poroelastic strain was also added in a thermoelastic constitutive equation. Chao et al. (2018) investigated the influence of the pore volume fraction change on the bending strength of $2 \mathrm{D}$ carbon/carbon composites, which demonstrates that the bending strength decreases greatly with the porosity increases, and the Mori-Tanaka approach was used to calculate the change of pore volume fraction.

To describe the damage of porous woven composites considering the pore structure, many researchers developed micromechanical-based models to predict the damage evolution and the overall behaviors of materials. Some researchers established micromechanics-based constitutive models for composites, using the Eshelby matrix-including solution and Mori-Tanaka homogenization solution (Liang et al., 2006; Mihai and Jefferson, 2017). Others focus on the micromechanical modeling considering the microstructure of composites. Chateau et al. (2015) analyzed the effect of the irregular shape of pores on the properties of materials by establishing a micromechanical model considering the heterogeneous microstructure. Nguyen and Bui (2019) defined the internal variables representing micromechanical failure processes within the localisation zone in the formulation and derived constitutive models, and two spatial scales were involved in the localised failure mechanisms, considering the macro scale of volume element and smaller scale of the localisation zone. Chen and Silberstein (2019) proposed a micromechanical-based damage model for non-woven materials, which can reproduce experimentally observed behaviours of material under uniaxial tensile loadings. However, due to the occurrence and mixing of several damage accumulation mechanisms during the loading process, the impact of damage should be considered from both micro and macro scales. Consequently, considering the hierarchical porosity in the matrix and fibers becomes important for predicting the damage evolution of composites.

Recent studies for composite porosity characterization techniques include micro-computed tomography (micro-CT) and Xray CT (Morales-Rodrguez et al., 2009; Tretiak and Smith, 2019; Larson et al., 2019), which are accurate in determining pore distribution but costly. On the other hand, the mercury intrusion method has been applied to obtain the porosity in the composites as well as the pore diameter, and performed well in the previous work (Yang and Yang, 2020). In this study, the mercury intrusion method is used to obtain the hierarchical porosity of the porous woven composites.

The principal objective of the present work is to develop a micromechanics framework to describe the effect of hierarchical porosity on material properties of the porous woven composites under thermomechanical loading. Toward this aim, adopting the idea of hierarchical porosity, a description of the constitutive law for determining the effective elastic properties of porous woven composites is proposed. Then a continuum damage mechanics framework that utilizes this constitutive law to describe the damage evolution in the matrix and fibers of the porous woven composites is presented. Finally, the proposed model is applied to a porous woven composite as the demonstrative example, and the prediction results are compared with the detailed experiments. The present work analyzed the effect of hierarchical porosity on the mechanical behavior of porous woven composites, and can be used to predict the elastic modulus of the materials with different scales of voids, providing the guidance in the manufacturing process of a specific material with selected modulus.

\section{Micromechanics-based model considering the contribution of hierarchical pores}

To estimate the effective elastic properties of porous woven composites, a micromechanics-based model is introduced considering the hierarchical porosity, the motivations of which are as follows:

(i) To interpret the influence of the hierarchical microstructure of a porous woven composite on its effective elastic modulus, thus enabling to consider hierarchical porous microstructures; (ii) To unify a single scheme for the estimation of the effective elastic properties that allows for a flexible application to various hierarchical microstructures of porous woven composites.

\subsection{Hierarchical porosity in composites}

Pores or voids in composites have obvious stratification characteristics for constituents at some scales. The observation of the scanning electron microscope (SEM) confirms this point. Fig. 1 shows the SEM observation of the porous woven oxide/oxide ceramic matrix composites (uncoated Nextel ${ }^{\mathrm{TM}} 610$ fibers and $\mathrm{Al}_{2} \mathrm{O}_{3}-\mathrm{SiO}_{2}-\mathrm{ZrO}_{2}$ matrix), which are used for the experimental validation later. As shown in Fig. 1(a), at the scale of the matrix, there are nanopores around particles formed in the manufacturing process, which are smaller than $0.1 \mu \mathrm{m}$. At the scale of fiber bundles, micropores exist between fibers due to the lack of matrix (Fig. 1(b)), with sizes of larger than $1 \mu \mathrm{m}$. At the scale of composite, sintering shrinkage cracks were found in the fibers and matrix which are perpendicular to the plies (Fig. 1(c)), and some airfilled cavities at the interface of matrix and fiber bundles, which can be considered as micropores, reveal small incompleteness in manufacturing, as demonstrated in Fig. 1(d).

Therefore, the concept of 'hierarchical porosity' has been introduced to describe two populations of pores of rather different sizes in the matrix and fiber bundles of porous woven composites (Yang et al., 2019): (i) the first population of pores can be found in the matrix with a few nanometers in diameter (they are referred to as nanopores), and (ii) the second population of pores, usually a few microns in diameter, can be observed at the matrix, fiber bundles and interface, these pores are referred to as micropores. Let $V$ be the volume of the composite; $w_{\mathrm{I}}$ is the domain occupied by the nanopores and $w_{\mathrm{II}}$ is the domain of the micropores. Then the nanoporosity and microporosity $\zeta_{\mathrm{I}}, \zeta_{\mathrm{II}}$ and the total porosity $\zeta$ can be expressed as:

$\zeta_{\mathrm{I}}=\frac{\left|w_{\mathrm{I}}\right|}{|V|}, \zeta_{\mathrm{II}}=\frac{\left|w_{\mathrm{II}}\right|}{|V|}, \zeta=\frac{\left|w_{\mathrm{I}}\right|+\left|w_{\mathrm{II}}\right|}{|V|}=\zeta_{\mathrm{I}}+\zeta_{\mathrm{II}}$

It should be noted that the different diameters of the nanopores and micropores (nanometers versus microns) make it possible to consider the pores in matrix and fiber bundles as well-separated. The fiber bundles contains micropores with volume fraction $\zeta_{\mathrm{f}}$, and the matrix contains nanopores and micropores with volume fraction $\zeta_{\mathrm{m}}$, as illustrated in Fig. 2, then

$\zeta_{\mathrm{f}}=\zeta_{\mathrm{II}}^{\mathrm{f}}, \zeta_{\mathrm{m}}=\zeta_{\mathrm{I}}+\zeta_{\mathrm{II}}^{\mathrm{m}}$

where $\zeta_{\mathrm{II}}=\zeta_{\mathrm{II}}^{\mathrm{f}}+\zeta_{\mathrm{II}}^{\mathrm{m}}$. 

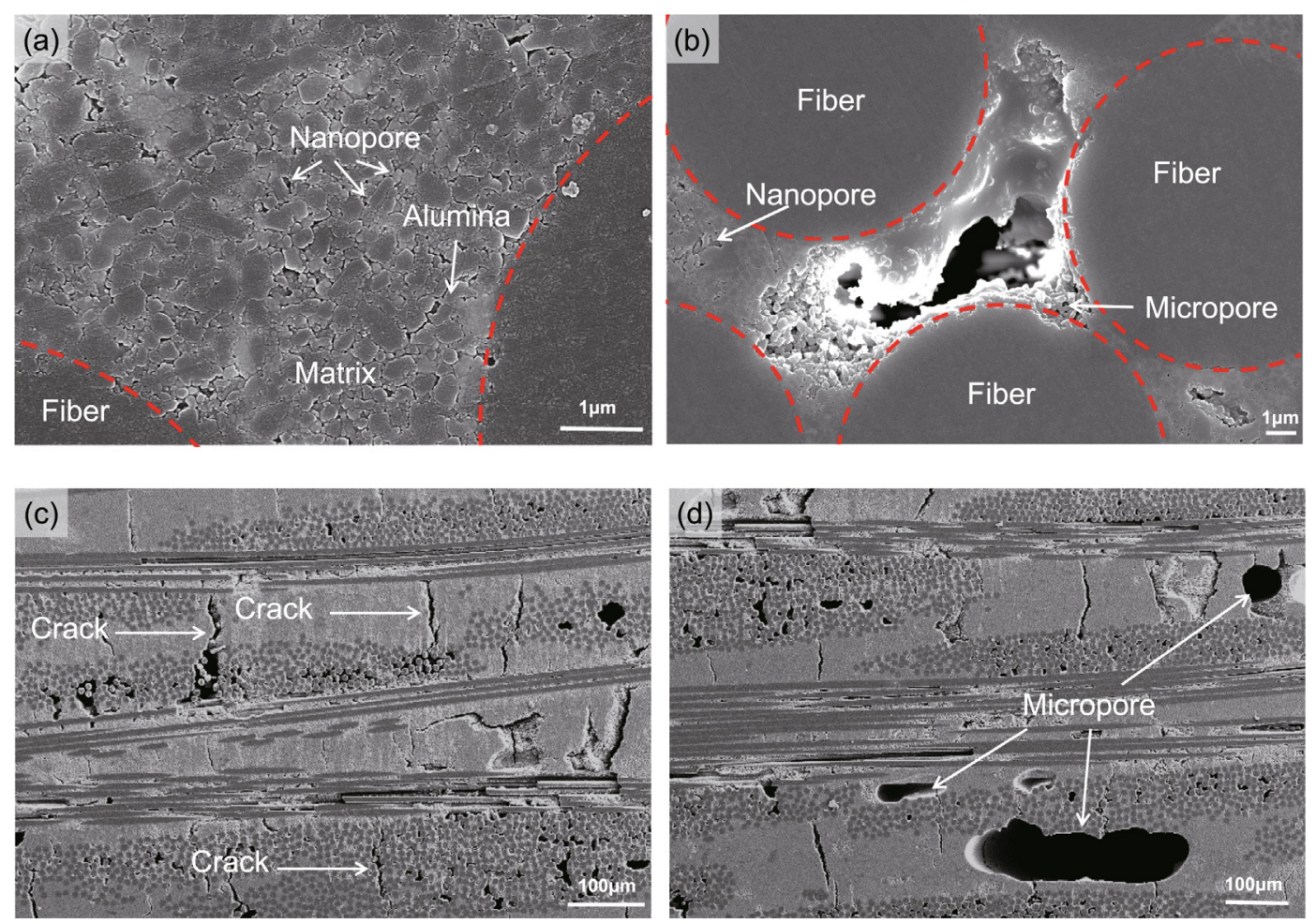

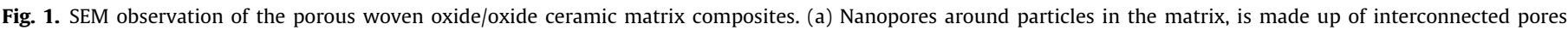

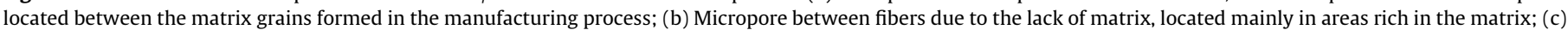

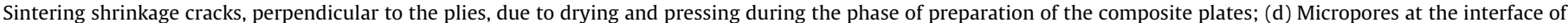
fibers and matrix revealing small incompleteness in manufacturing.

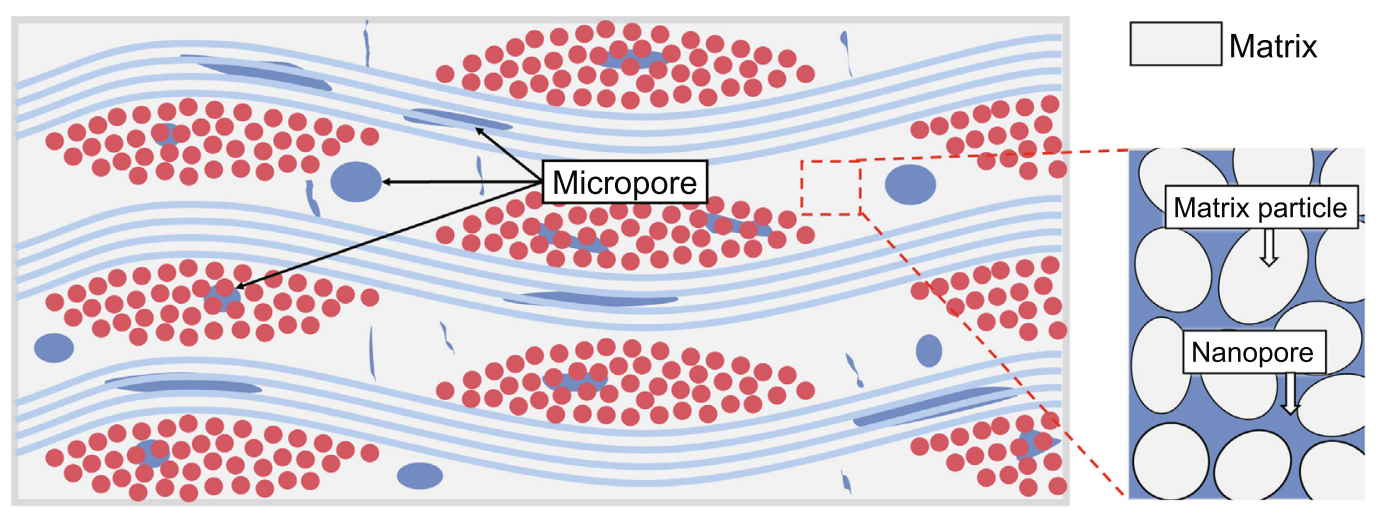

Fig. 2. Porosity in the fiber bundles and matrix. The fiber bundles contain micropores and the matrix contains nanopores and micropores.

Thermomechanical loading will induce microstructural changes, which result in the decrease of mechanical properties. Generally, the evolution of porosity for composites under thermomechanical loading can be divided into two stages: Firstly, when suffering from the thermomechanical loading, the material is subjected to the thermal stress through the thickness. Its surface is at a lower temperature, resulting in tensile stress, and the interior is at a higher temperature, resulting in compression stress, which may lead to the generation and expansion of the original micropores. The microporosity will rapidly increase, and there are some small cracks initial in the matrix, leading the nanoporosity to increase. However, as the time increase, the nanoporosity begins to decrease and finally reaches a saturated stage, this may be because that the original nanopores remain unchanged under thermomechanical loading, as the original nanopores are the pores around particles in the matrix, and the size of particles remains unchanged during the thermomechanical loading. The crack density reaches a saturation level with crack growth. The microporosity increases to the saturation level with newly formed pores and the pores coalesce.

With the increase of porosity, the effective loading area of the composite decreases, implying that the material properties degenerate with porosity. To incorporate the influence of pores evolution on the macroscopic response of materials, simplifying assumptions are introduced to isolate the effects of hierarchical porosity on the mechanical properties of matrix and fibers.

(i) The nanopores exist in the matrix, and their volume fraction is assumed to be a constant during the thermomechanical loading. In other words, the nanopores are little influenced by the thermomechanical loads.

(ii) The micropores exist in the matrix and fiber bundles, and the microporosity increases with the thermomechanical load- 
ing, which implies there are increasing material damage in the fiber bundles and matrix (Yang et al., 2019).

\subsection{Constitutive model}

A new constitutive model of porous woven composites considering hierarchical porosity changes is proposed in this section. The pores in composites can be regarded as the third phase except for matrix and fibers, and the inclusion theory of the Mori-Tanaka solution is applied to describe the pores in the constitutive model, which assumes that the pores are inclusions in materials but the stiffness of them is zero.

Consider a representative volume element (RVE) consisting the matrix, fibers and pore phase with volume $V$. The average stress and strain of the RVE can be defined as the average stress and strain of the point dividing the total volume $V$ :

$\overline{\boldsymbol{\sigma}}=\frac{1}{V} \int_{V} \boldsymbol{\sigma}(\mathbf{x}) \mathrm{d} v ; \overline{\boldsymbol{\varepsilon}}=\frac{1}{V} \int_{V} \boldsymbol{\varepsilon}(\mathbf{x}) \mathrm{d} v$

The total volume $V$ is composed of the matrix pore volume $V_{\mathrm{p}}^{\mathrm{m}}$, the matrix volume $V_{\mathrm{m}}$, the fiber pore volume $V_{\mathrm{p}}^{\mathrm{f}}$ and the fiber phase volume $V_{\mathrm{f}}$, as mentioned in Section 2.1.

Therefore, the average stress and strain in Eq. (3) can be expressed by the four volumes. The following relationship is obtained:

$$
\begin{aligned}
& \overline{\boldsymbol{\sigma}}=\zeta_{\mathrm{m}} \overline{\boldsymbol{\sigma}}_{\mathrm{p}}^{\mathrm{m}}+f_{\mathrm{m}} \overline{\boldsymbol{\sigma}}^{\mathrm{m}}+\zeta_{\mathrm{f}} \overline{\boldsymbol{\sigma}}_{\mathrm{p}}^{\mathrm{f}}+f_{\mathrm{f}} \overline{\boldsymbol{\sigma}}^{\mathrm{f}} \\
& \overline{\boldsymbol{\varepsilon}}=\zeta_{\mathrm{m}} \overline{\boldsymbol{\varepsilon}}_{\mathrm{p}}^{\mathrm{m}}+f_{\mathrm{m}} \overline{\boldsymbol{\varepsilon}}^{\mathrm{m}}+\zeta_{\mathrm{f}} \overline{\boldsymbol{\varepsilon}}_{\mathrm{p}}^{\mathrm{f}}+f_{\mathrm{f}} \overline{\boldsymbol{\varepsilon}}^{\mathrm{f}}
\end{aligned}
$$

where $\overline{\boldsymbol{\sigma}}^{k}, \overline{\boldsymbol{\varepsilon}}^{k}(k=\mathrm{m}, \mathrm{f})$ are the average stress and strain in the matrix and fiber; $\overline{\boldsymbol{\sigma}}_{\mathrm{p}}^{k}, \overline{\boldsymbol{\varepsilon}}_{\mathrm{p}}^{k}$ are the average stress and strain in the pores of matrix and fibers; $f_{k}$ is the volume fraction of fibers and matrix. The average stress and strain in each volume satisfies:

$$
\begin{aligned}
& \overline{\boldsymbol{\sigma}}_{\mathrm{p}}^{\mathrm{m}}=\boldsymbol{E}_{\mathrm{p}}^{\mathrm{m}}: \overline{\boldsymbol{\varepsilon}}_{\mathrm{p}}^{\mathrm{m}} ; \overline{\boldsymbol{\sigma}}_{\mathrm{p}}^{\mathrm{f}}=\boldsymbol{E}_{\mathrm{p}}^{\mathrm{f}}: \overline{\boldsymbol{\varepsilon}}_{\mathrm{p}}^{\mathrm{f}} ; \\
& \overline{\boldsymbol{\sigma}}^{\mathrm{m}}=\boldsymbol{E}^{\mathrm{m}}: \overline{\boldsymbol{\varepsilon}}^{\mathrm{m}} ; \overline{\boldsymbol{\sigma}}^{\mathrm{f}}=\boldsymbol{E}^{\mathrm{f}}: \overline{\boldsymbol{\varepsilon}}^{\mathrm{f}}
\end{aligned}
$$

where $\boldsymbol{E}_{\mathrm{p}}^{\mathrm{m}}, \boldsymbol{E}^{\mathrm{m}}, \boldsymbol{E}_{\mathrm{p}}^{\mathrm{f}}$ and $\boldsymbol{E}^{\mathrm{f}}$ are the stiffness tensors of the pores in matrix, the matrix, the pores in fibers and the fibers, respectively, and $\boldsymbol{E}_{\mathrm{p}}^{\mathrm{m}}=\boldsymbol{E}_{\mathrm{p}}^{\mathrm{f}}=0$.

Similar to the inclusions, the pores in the material may disturb the homogeneous far-field strain field. Therefore, the strain of the pores (assuming that the pores are inclusions in the material) can be divided into the disturbance part $\boldsymbol{\varepsilon}_{\mathrm{d}}$ and the far-field uniform part $\boldsymbol{\varepsilon}_{0}$, as:

$$
\begin{aligned}
& \boldsymbol{\varepsilon}_{\mathrm{p}}^{\mathrm{m}}=\boldsymbol{\varepsilon}_{0}+\boldsymbol{\varepsilon}_{\mathrm{dp}}^{\mathrm{m}} \text { in } V_{\mathrm{p}}^{\mathrm{m}} \\
& \boldsymbol{\varepsilon}_{\mathrm{p}}^{\mathrm{f}}=\boldsymbol{\varepsilon}_{0}+\boldsymbol{\varepsilon}_{\mathrm{dp}}^{\mathrm{f}} \text { in } V_{\mathrm{p}}^{\mathrm{f}} \\
& \boldsymbol{\varepsilon}^{\mathrm{m}}=\boldsymbol{\varepsilon}_{0}+\boldsymbol{\varepsilon}_{\mathrm{d}}^{\mathrm{m}} \text { in } V_{\mathrm{m}} \\
& \boldsymbol{\varepsilon}^{\mathrm{f}}=\boldsymbol{\varepsilon}_{0}+\boldsymbol{\varepsilon}_{\mathrm{d}}^{\mathrm{f}} \text { in } V_{\mathrm{f}}
\end{aligned}
$$

Thus, the stress of the pores can be obtained:

$$
\begin{aligned}
& \boldsymbol{\sigma}_{\mathrm{p}}^{\mathrm{m}}=\boldsymbol{E}_{\mathrm{p}}^{\mathrm{m}}:\left(\boldsymbol{\varepsilon}_{0}+\boldsymbol{\varepsilon}_{\mathrm{dp}}^{\mathrm{m}}\right) \quad i n V_{\mathrm{p}}^{\mathrm{m}} \\
& \boldsymbol{\sigma}_{\mathrm{p}}^{\mathrm{f}}=\boldsymbol{E}_{\mathrm{p}}^{\mathrm{f}}:\left(\boldsymbol{\varepsilon}_{0}+\boldsymbol{\varepsilon}_{\mathrm{dp}}^{f}\right) \quad i n V_{\mathrm{p}}^{\mathrm{f}}
\end{aligned}
$$

Consider one equivalent volume that has the same size and shape as the pores in the matrix, and the material is the same as the matrix, one equivalent volume that has the same size and shape as the pores in fibers, and the material is the same as the fibers, then the strain in the equivalent volume can be seen as eigenstrain $\boldsymbol{\varepsilon}^{*}$, which is used to approximate the stress field inside the pore volume. The stress field of the pores can then be expressed as,

$$
\begin{aligned}
& \boldsymbol{\sigma}_{\mathrm{p}}^{\mathrm{m}}=\boldsymbol{E}^{\mathrm{m}}:\left(\boldsymbol{\varepsilon}_{0}+\boldsymbol{\varepsilon}_{\mathrm{dp}}^{\mathrm{m}}-\boldsymbol{\varepsilon}^{*}\right)=\boldsymbol{E}_{\mathrm{p}}^{\mathrm{m}}:\left(\boldsymbol{\varepsilon}_{0}+\boldsymbol{\varepsilon}_{\mathrm{dp}}^{\mathrm{m}}\right) \text { in } V_{\mathrm{p}}^{\mathrm{m}} \\
& \boldsymbol{\sigma}_{\mathrm{p}}^{\mathrm{f}}=\boldsymbol{E}^{\mathrm{f}}:\left(\boldsymbol{\varepsilon}_{0}+\boldsymbol{\varepsilon}_{\mathrm{dp}}^{\mathrm{f}}-\boldsymbol{\varepsilon}^{*}\right)=\boldsymbol{E}_{\mathrm{p}}^{\mathrm{f}}:\left(\boldsymbol{\varepsilon}_{0}+\boldsymbol{\varepsilon}_{\mathrm{dp}}^{\mathrm{f}}\right) \text { in } V_{\mathrm{p}}^{\mathrm{f}}
\end{aligned}
$$

Bedsides, the disturbance strain $\boldsymbol{\varepsilon}_{\mathrm{d}}^{\mathrm{p}}$ can be expressed by $\boldsymbol{\varepsilon}^{*}$ :

$$
\begin{aligned}
& \boldsymbol{\varepsilon}_{\mathrm{dp}}^{\mathrm{m}}=\boldsymbol{S}_{\mathrm{m}}: \boldsymbol{\varepsilon}_{\mathrm{m}}^{*} \text { in } V_{\mathrm{p}}^{\mathrm{m}} \\
& \boldsymbol{\varepsilon}_{\mathrm{dp}}^{\mathrm{f}}=\boldsymbol{S}_{\mathrm{f}}: \boldsymbol{\varepsilon}_{\mathrm{f}}^{*} \text { in } V_{\mathrm{p}}^{\mathrm{f}}
\end{aligned}
$$

where $\boldsymbol{S}_{\mathrm{f}}$ is a function of fiber stiffness and the shape of the pores in fibers; $\boldsymbol{S}_{\mathrm{m}}$ is a function of matrix stiffness and the shape of the pores in the matrix; Substituting Eq. (9) into Eq. (8), one obtains

$$
\begin{aligned}
& \boldsymbol{\varepsilon}_{\mathrm{m}}^{*}=\left(\boldsymbol{A}_{\mathrm{m}}-\boldsymbol{S}_{\mathrm{m}}\right)^{-1}: \boldsymbol{\varepsilon}_{0} \\
& \boldsymbol{\varepsilon}_{\mathrm{f}}^{*}=\left(\boldsymbol{A}_{\mathrm{f}}-\boldsymbol{S}_{\mathrm{f}}\right)^{-1}: \boldsymbol{\varepsilon}_{0}
\end{aligned}
$$

where $\boldsymbol{A}_{\mathrm{m}}=\left(\boldsymbol{E}^{\mathrm{m}}-\boldsymbol{E}_{\mathrm{i}}^{\mathrm{m}}\right)^{-1}: \boldsymbol{E}^{\mathrm{m}}, \boldsymbol{A}_{\mathrm{f}}=\left(\boldsymbol{E}^{\mathrm{f}}-\boldsymbol{E}_{\mathrm{i}}^{\mathrm{f}}\right)^{-1}: \boldsymbol{E}^{\mathrm{f}}$. The average stress and strain of the pores can be obtain by substituting $\varepsilon_{k}^{*}$ into Eqs. (6) and (8),

$$
\begin{aligned}
& \overline{\boldsymbol{\varepsilon}}_{\mathrm{p}}^{k}=\boldsymbol{\varepsilon}_{0}+\boldsymbol{S}_{k}:\left(\boldsymbol{A}_{k}-\boldsymbol{S}_{k}\right)^{-1}: \boldsymbol{\varepsilon}_{0} \\
& \overline{\boldsymbol{\sigma}}_{\mathrm{p}}^{k}=\boldsymbol{E}^{k}:\left(\boldsymbol{\varepsilon}_{0}+\left(\boldsymbol{S}_{k}-\boldsymbol{I}\right):\left(\boldsymbol{A}_{k}-\boldsymbol{S}_{k}\right)^{-1}: \boldsymbol{\varepsilon}_{0}\right)
\end{aligned}
$$

where $\boldsymbol{I}$ is the 4 th order symmetric identity tensor. The average strain in matrix and fibers are (Huang and Talreja, 2005),

$$
\begin{aligned}
& \overline{\boldsymbol{\varepsilon}}^{\mathrm{m}}=\boldsymbol{\varepsilon}_{0}^{\mathrm{m}}, \quad \overline{\boldsymbol{\sigma}}^{\mathrm{m}}=\boldsymbol{E}^{\mathrm{m}}: \boldsymbol{\varepsilon}_{0}^{\mathrm{m}} \quad \operatorname{in} V_{\mathrm{m}} \\
& \overline{\boldsymbol{\varepsilon}}^{\mathrm{f}}=\boldsymbol{\varepsilon}_{0}^{\mathrm{f}}, \quad \overline{\boldsymbol{\sigma}}^{\mathrm{f}}=\boldsymbol{E}^{\mathrm{f}}: \boldsymbol{\varepsilon}_{0}^{\mathrm{f}} \quad \operatorname{in} V_{\mathrm{f}}
\end{aligned}
$$

Substituting Eqs. (11), (12) into Eq. (4), and considering $\boldsymbol{E}=\overline{\boldsymbol{\sigma}}: \overline{\boldsymbol{\varepsilon}}^{-1}$, the stiffness in the RVE is expressed as,

$$
\begin{aligned}
& \boldsymbol{E}=\left\{\begin{array}{l}
\boldsymbol{E}^{\mathrm{m}}:\left\{\left(1-\zeta_{\mathrm{f}}-f_{\mathrm{f}}\right) \boldsymbol{I}+\zeta_{\mathrm{m}}\left(\boldsymbol{S}_{\mathrm{m}}-\boldsymbol{I}\right):\left(\boldsymbol{A}_{\mathrm{m}}-\boldsymbol{S}_{\mathrm{m}}\right)^{-1}\right\} \\
+\boldsymbol{E}^{\mathrm{f}}:\left\{\left(1-\zeta_{\mathrm{m}}-f_{\mathrm{m}}\right) \boldsymbol{I}+\zeta_{\mathrm{f}}\left(\boldsymbol{S}_{\mathrm{f}}-\boldsymbol{I}\right):\left(\boldsymbol{A}_{\mathrm{f}}-\boldsymbol{S}_{\mathrm{f}}\right)^{-1}\right\}
\end{array}\right\} \\
& :\left\{\boldsymbol{I}+\zeta_{\mathrm{m}} \boldsymbol{S}_{\mathrm{m}}:\left(\boldsymbol{A}_{\mathrm{m}}-\boldsymbol{S}_{\mathrm{m}}\right)^{-1}+\zeta_{\mathrm{f}} \boldsymbol{S}_{\mathrm{f}}:\left(\boldsymbol{A}_{f}-\boldsymbol{S}_{\mathrm{f}}\right)^{-1}\right\}^{-1}
\end{aligned}
$$

Considering $\boldsymbol{E}_{\mathrm{p}}^{\mathrm{m}}=\boldsymbol{E}_{\mathrm{p}}^{\mathrm{f}}=0$, Eq. (13) becomes,

$$
\mathbf{E}=\left\{f_{\mathrm{m}} \mathbf{E}^{\mathrm{m}}+f_{\mathrm{f}} \mathbf{E}^{\mathrm{f}}\right\}:\left\{\boldsymbol{I}+\zeta_{\mathrm{m}} \mathbf{S}_{\mathrm{m}}:\left(\boldsymbol{I}-\mathbf{S}_{\mathrm{m}}\right)^{-1}+\zeta_{\mathrm{f}} \mathbf{S}_{\mathrm{f}}:\left(\boldsymbol{I}-\mathbf{S}_{\mathrm{f}}\right)^{-1}\right\}^{-1}
$$

Eq. (14) provides the analytical solution of effective stiffness tensor of the material consisting of hierarchical pores, expressed in term of stiffness and compliance tensors. For the convenience of comparison with the experimental results, the tensor expression is transformed into a scalar form and expressed as a function of individual elastic modulus with pores (Yang et al., 2019),

$$
\begin{aligned}
& E_{1}=\eta_{0} E_{\mathrm{f}} \varpi f_{\mathrm{f}}\left(1-\zeta_{\mathrm{f}}-\zeta_{\mathrm{m}}\right)^{\mathrm{a}}+E_{\mathrm{m}} f_{\mathrm{m}}(1-\varpi)\left(1-\zeta_{\mathrm{f}}-\zeta_{\mathrm{m}}\right)^{\mathrm{a}} \\
& E_{2}=\frac{\eta_{0}\left(1-\zeta_{\mathrm{f}}-\zeta_{\mathrm{m}}\right)^{\mathrm{a}-2} E_{\mathrm{f}} E_{\mathrm{m}}}{\left[\eta_{0}(1-\varpi) E_{\mathrm{f}} f_{\mathrm{m}}+\varpi E_{\mathrm{m}} f_{\mathrm{f}}\right]}
\end{aligned}
$$

where $E_{1}$ and $E_{2}$ are the elastic modulus of the principal directions of the material, $\eta_{0}$ the parameter considering the effects of the fiber orientation (Baghaei et al., 2014), for the unidirectional fiber $\eta_{0}=1$; $\varpi$ is a weight factor for representing the pores in fibers and matrix,and is decided by the porosity in fibers and matrix; $a$ is a material parameter obtained by experiments. $E_{\mathrm{f}}^{0}$ and $E_{\mathrm{m}}^{0}$ devote the elastic modulus of the fibers and matrix without pores, respectively. In this case, the elastic modulus of the fibers and matrix are,

$$
\begin{aligned}
E_{\mathrm{f}} & =\eta_{0}\left(1-\zeta_{\mathrm{f}}-\zeta_{\mathrm{m}}\right)^{\mathrm{a}-1} E_{\mathrm{f}}^{0} \\
E_{\mathrm{m}} & =\left(1-\zeta_{\mathrm{f}}-\zeta_{\mathrm{m}}\right)^{\mathrm{a}-1} E_{\mathrm{m}}^{0}
\end{aligned}
$$




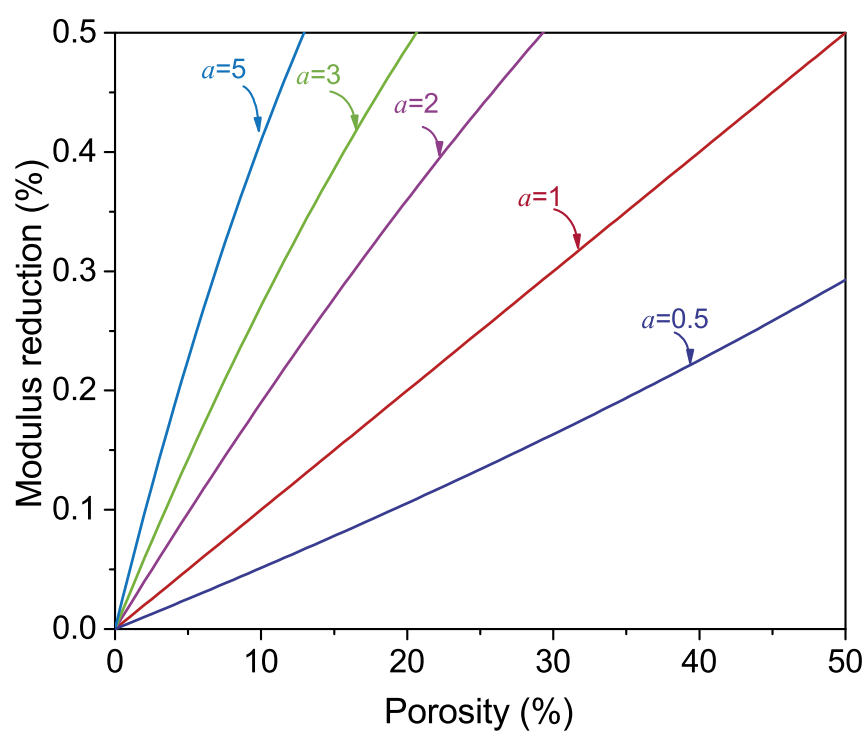

Fig. 3. The parameter study of Eq. (15) to understand the effect of material parameter $a$ on the form of the effective elastic modulus.

The advantage of Eq. (15) is that the contributions of hierarchical porous can be examined on the material macroscopic mechanical responses. If the porosity changes in the materials, which can be caused by the thermomechanical loading and so on, the effective elastic modulus can be obtained by using Eq. (15). The model can not only apply to the porous woven composites subjected to thermomechanical loading but also other loadings that cause the porosity changes in the materials.

Fig. 3 shows the parameter study of Eq. (15) to understand the effect of material parameter $a$ on the form of the effective elastic modulus. It is found that the effective elastic modulus displays different shapes of the curves with different values of $a$. If the porosity and matrix and fiber volume fractions of some materials have been known, then the effective modulus of the material can be predicted using Eq. (15). Fig. 4 shows the predicted modulus for different porosity and matrix and fiber volume fractions, and each point in the curves refers to a particular material with corresponding porosity and matrix and fiber volume fractions. For the present work, the porosity in the material was assumed less than $40 \%$, the fibers and matrix volume fraction changed up to $70 \%$.

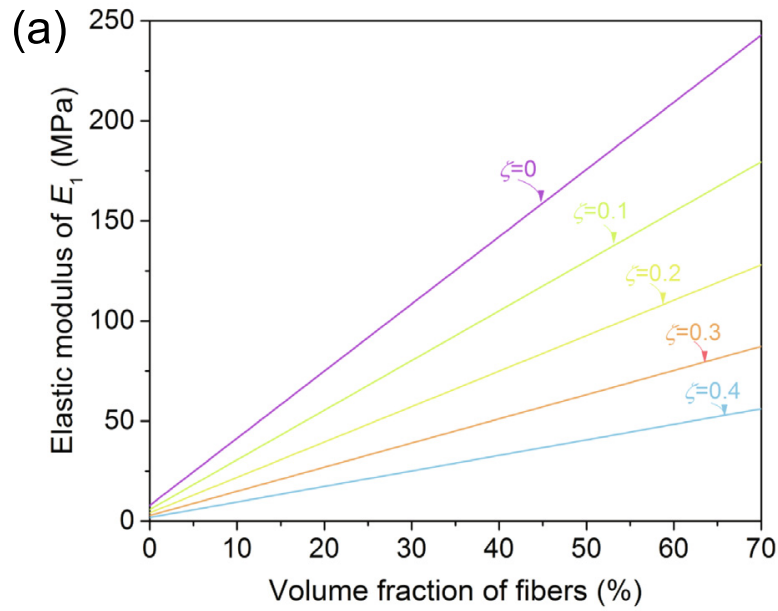

\section{Thermomechanical damage evolution}

Models representing thermomechanical damage evolutions in the matrix and fibers are briefly discussed in this section. The linear elastic-damage constitutive framework is applied for the damage behavior of fibers and matrix. Two CDM-based scalar damage variables are introduced to predict the reduction of stiffness in the fibers and matrix, which are defined as:

$D_{\mathrm{f}}=1-\frac{\tilde{E}_{\mathrm{f}}}{E_{\mathrm{f}}^{0}}, \quad D_{\mathrm{m}}=1-\frac{\tilde{E}_{\mathrm{m}}}{E_{\mathrm{m}}^{0}}$

where subscript $\mathrm{f}$ and $\mathrm{m}$ denote the fibers and matrix, respectively. $\tilde{E}$ is the elastic modulus of damaged material and $E^{0}$ is the elastic modulus of undamaged material. Consequently, the strain energy density is defined as:

$\rho \psi=\rho \psi\left(\varepsilon_{i j}, D_{\mathrm{f}}, D_{\mathrm{m}}\right)=\frac{1}{2} \varepsilon_{i j} \sigma_{i j}$

where $\rho$ is the density of the material, and $\psi$ is the strain energy,

\subsection{Matrix damage evolution}

The strain energy density release rate $Y_{m}$ associated to $D_{\mathrm{m}}$ is introduced to describe the matrix damage evolution, which is defined as (Lemaitre and Desmorat, 2005):

$Y_{\mathrm{m}}=\rho \frac{\partial \psi}{\partial D_{\mathrm{m}}}=\frac{1}{2} \frac{\left[\sigma_{11}^{\mathrm{m}} \varepsilon_{11}^{\mathrm{m}}+\sigma_{22}^{\mathrm{m}} \varepsilon_{22}^{\mathrm{m}}\right]}{\left(1-D_{\mathrm{m}}\right)}$

Many damage models use a power law to describe the relationship between the damage and the strain energy density release rate, which can not predict accurately and are difficult to accurately describe damage evolution. To build the effective quantities in the material properties characterization and damage evolution under thermomechanical loading condition, the potential function is introduced for the matrix damage evolution, which can predict damage initiation and growth under the elastic state, and is defined by,

$\mathcal{F}\left(D_{\mathrm{m}}\right)=Y_{\mathrm{m}}-\mathcal{L}\left(D_{\mathrm{m}}\right)$,

where $\mathcal{L}$ is a function of damage, and it can represent the material resistance against damage. Referring to the principle of $\mathrm{CDM}$, the matrix damage occurs when the damage driving force $Y \mathrm{~m}$ reaches the material resistance $\mathcal{L}$.

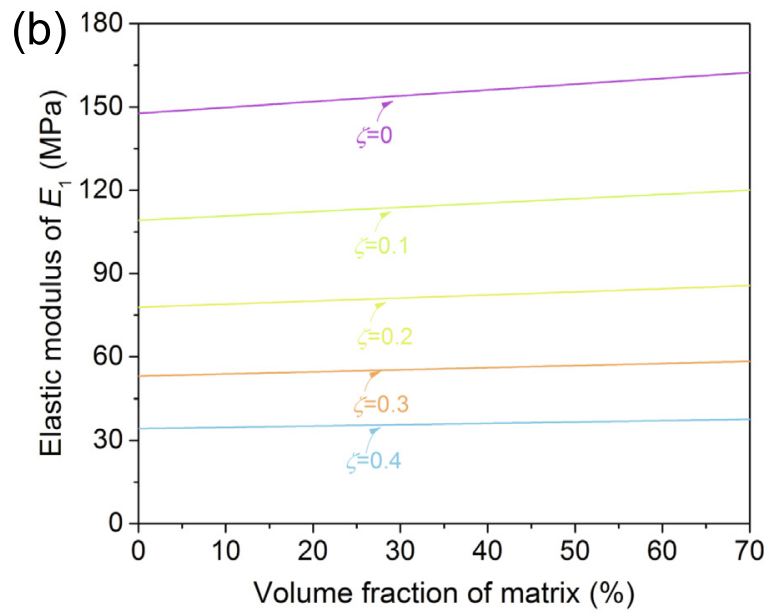

Fig. 4. The predicted modulus obtained by Eq. (15) for different porosity and matrix and fiber volume fractions. 
The material resistance $\mathcal{L}$ can be defined as the form (Cicekli et al., 2007),

$\mathcal{L}=\exp \left(\frac{D_{\mathrm{m}}}{\beta D_{\mathrm{m}}^{\mathrm{cr}}}\right)$

where $D_{\mathrm{m}}^{\mathrm{cr}}$ is the damage at failure, $\beta$ is a model parameter, and $Y_{\mathrm{th}, \mathrm{m}}$ is the initial energy density release rate as the threshold.

Considering the maximum dissipation principle, the matrix damage evolution law is written as,

$\dot{D}_{\mathrm{m}}=\dot{\lambda} \frac{\partial \mathcal{F}\left(D_{\mathrm{m}}\right)}{\partial Y_{\mathrm{m}}}=\dot{\lambda}_{\mathrm{m}}$

where $\dot{\lambda}_{\mathrm{m}}$ is the damage multiplier, according to the Kuhn-Tucker relations, as

$$
\begin{cases}\dot{\lambda}_{\mathrm{m}} \geqslant 0 & \text { for } \mathcal{F}\left(Y, D_{\mathrm{m}}\right)=0, \\ \dot{\lambda}_{\mathrm{m}}=0 & \text { for } \mathcal{F}\left(Y, D_{\mathrm{m}}\right)<0,\end{cases}
$$

it is non-negative under thermomechanical conditions, and $\dot{\lambda}_{\mathrm{m}}$ is determined by the damage consistency condition, as

$\mathrm{d} \mathcal{F}\left(D_{\mathrm{m}}\right)=\frac{\partial \mathcal{F}\left(D_{\mathrm{m}}\right)}{\partial Y_{\mathrm{m}}} \dot{Y}_{\mathrm{m}}-\frac{\partial \mathcal{L}}{\partial D_{\mathrm{m}}} \dot{\lambda}_{\mathrm{m}}=0$

Then, the matrix damage evolution law can be deduced as

$\dot{D}_{\mathrm{m}}=\frac{D_{\mathrm{m}}^{\mathrm{cr}} \beta}{Y_{\mathrm{m}}} \dot{Y}_{\mathrm{m}}$,

Integrating Eq. (24) over $\left[Y_{\mathrm{th}, \mathrm{m}}, Y_{\mathrm{m}}\right]$, the explicit matrix damage expression is in the form as,

$D_{\mathrm{m}}=D_{\mathrm{m}}^{\mathrm{ini}}+\beta D_{\mathrm{m}}^{\mathrm{cr}}\left[\ln Y_{\mathrm{m}}-\ln Y_{\mathrm{th}, \mathrm{m}}\right]$

Eq. (25) gives the damage evolution law of the matrix between the initial state or the pre-damage state and the fracture failure state. Obviously, the matrix damage is characterized by the parameter $\beta$, the initial damage resistance $Y_{\mathrm{th}, \mathrm{m}}$, the initial damage $D_{\mathrm{m}}^{\mathrm{ini}}$ and the failure damage $D_{\mathrm{m}}^{\mathrm{cr}}$.

\subsection{Fibers damage evolution}

Fibers damage modeling is an issue specific to the porous woven composites as they contain a large number of fibers, and the breaking of fibers may have consequences on the composite damage behavior. As for the fibers subjected to global loading, the load will transmit from each failed fiber to the intact fibers, and there may be some microcracks considered as micropores to induce a loss of energy and cause the final failure of the fiber. For precisely estimate the damage evolution, the statistical distribution of the micropores in the fibers must be taken into account.

To illustrate this point, $\mathrm{W}$. Weibull proposed a model of the probability of failure considering the stress and the volume (Rajan and Zok, 2012; Chao et al., 2018). The fracture probability of the fibers under the stress $\sigma_{\mathrm{f}}^{*}$ can be described by the following Weibull function,

$\mathcal{F}\left(\sigma_{\mathrm{f}}^{*}\right)=1-\exp \left\{-V\left(\frac{\sigma_{\mathrm{f}}^{*}}{\sigma_{\mathrm{w}}}\right)^{\alpha}\right\}$

where $\sigma_{w}$ is the scale parameter, and $\alpha$ is the shape parameter; $V$ denotes the stressed volume of fibers. Assuming that the total number of fibers is $\varrho$, then the number of broken fibers can be determined,

$\varrho_{b}=\mathcal{F}\left(\sigma_{\mathrm{f}}^{*}\right) \varrho$

and the number of unbroken fibers is $\varrho-\varrho_{b}=\left(1-\mathcal{F}\left(\sigma_{\mathrm{f}}^{*}\right)\right)$.
The applied load is

$\mathcal{P}_{\mathrm{f}}=\sum_{i} \sigma_{i} \mathcal{S}_{0}$

where $\mathcal{S}_{0}$ is the area of cross section, $\sigma_{i}$ is the stress applied to each fiber, for the broken fibers $\sigma_{i}=0$; for the remaining fibers, $\sigma_{i}=E_{\mathrm{f}}^{0} \varepsilon$. Then,

$\mathcal{P}_{\mathrm{f}}=E_{\mathrm{f}}^{0} \varepsilon_{\mathrm{f}} \mathcal{S}_{0}\left(1-\mathcal{F}\left(\sigma_{\mathrm{f}}^{*}\right)\right) \varrho=E_{\mathrm{f}}^{0} \varepsilon_{\mathrm{f}} \mathcal{S}\left(1-\mathcal{F}\left(\sigma_{\mathrm{f}}^{*}\right)\right)$

where $E_{\mathrm{f}}^{0}$ is the elastic modulus of fibers, $S$ is the remain area of the cross section which carries loading.

For fibers, the probability density of micropores in the applied plane is considered as the fiber damage variable of CDM, $D_{\mathrm{f}}$, then $D_{\mathrm{f}}=\mathcal{F}\left(\sigma_{\mathrm{f}}^{*}\right)$. The applied load $\mathcal{P}_{\mathrm{f}}$ on the fiber bundles has been defined by Eq. (29), then the mean applied stress of fiber bundles is obtained as,

$\bar{\sigma}_{\mathrm{f}}=\frac{\mathcal{P}_{\mathrm{f}}}{\mathcal{S}}=E_{\mathrm{f}}^{0} \varepsilon_{\mathrm{f}}\left(1-\mathcal{F}\left(\sigma_{\mathrm{f}}^{*}\right)\right)=E_{\mathrm{f}}^{0} \varepsilon_{\mathrm{f}}\left(1-D_{\mathrm{f}}\right)$

The damage evolution is obtained from Eq. (26) and (30),

$D_{\mathrm{f}}=1-\exp \left\{-\left(\frac{E_{\mathrm{f}}^{0} \varepsilon_{\mathrm{f}}}{\sigma_{\mathrm{w}}}\right)^{\alpha}\right\}$

\section{Results and discussion}

As a concrete example, we apply the proposed model to the oxide/oxide ceramic matrix composites (CMCs), which were manufactured using uncoated Nextel ${ }^{\mathrm{TM}} 610\left(99 \% \alpha-\mathrm{Al}_{2} \mathrm{O}_{3}\right)$ fibers and $\mathrm{Al}_{2} \mathrm{O}_{3}-\mathrm{SiO}_{2}-\mathrm{ZrO}_{2}$ matrix. The thermomechanical loading is applied to the materials in the form of cyclic thermal shocks. Firstly, the previously published experimental characterization results of the CMCs are summarized. Then, the identification of the parameters used in the model are presented, and the damage evolutions of matrix and fibers are predicted and compared with the experimental data.

\subsection{Experimental results summary}

Experimental results and mechanical characterization of the oxide/oxide CMCs are detailed in previous works (Yang and Liu, 2020) and are briefly summarized here. According to the application of the material, the cyclic thermal shock tests were conducted at $1100^{\circ} \mathrm{C}$. After each thermal shock, the specimen was put into the Micromeritics Autopore IV 9510 porosimeter to determine hierarchical porosities as well as generate the change of pore size distribution of the CMCs under thermomechanical loading.

According to the mercury intrusion results and the SEM observation, the nanopores in the CMCs are defined as the pore diameter smaller than $200 \mathrm{~nm}$, and the micropores are considered as pore diameter larger than $200 \mathrm{~nm}$. Fig. 5 shows the evolution of hierarchical porosities of the whole material with the increase of thermal shock cycles. The total porosity of the material is increased with the thermal shock cycles, which is the sum of the nanoporosity and the microporosity. The nanoporosity experiences a rapid increase, then decreases and finally reaches a saturated stage, this may due to that there are some small cracks initial in the matrix in the beginning, and the decrease after a single thermal shock can be regarded as the nanopores transferring into micropores, then the crack grows with the thermal shock cycles. The original nanopores remain unchanged, due to that the original nanopores are the pores around particles in the matrix, and the size of particles remains unchanged during the thermomechanical loading. As for the microporosity, it also experiences a rapid increase, then gradually 


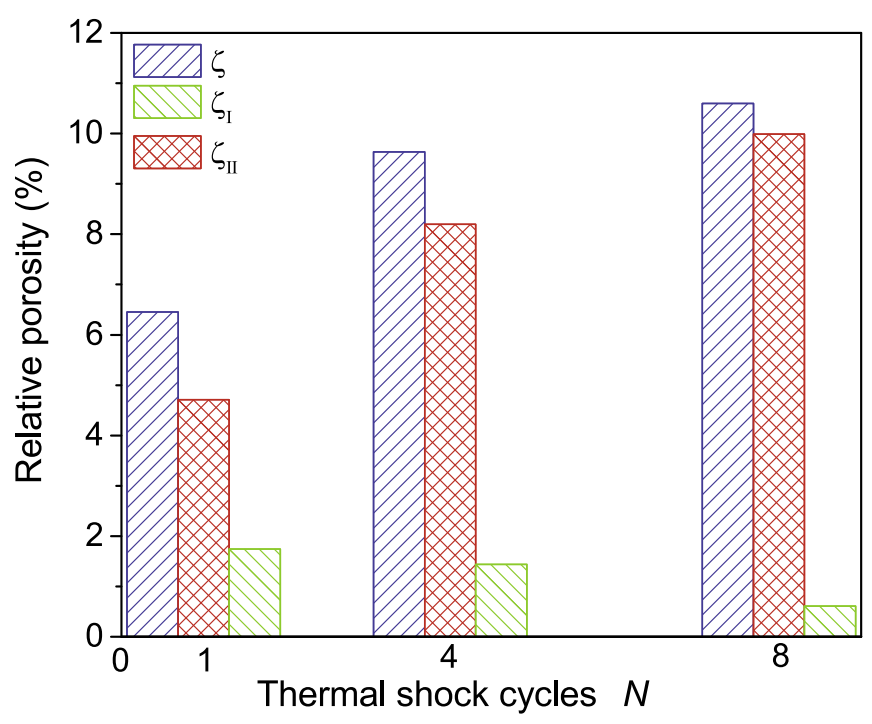

Fig. 5. The evolution of hierarchical porosities of the whole material with the thermal shock cycles $N$ for the shock temperatures equal to $1100{ }^{\circ} \mathrm{C}$.

increases to a saturation level with thermal shock cycles, which is due to the accumulation of micro defects with newly formed pores and the pores coalesce, and finally the crack density reaches saturation level with crack growth.

The mechanical properties of the thermal shocked CMCs were also quantified by uniaxial monotonic tensile loadings in the fiber direction (the weft direction). The experiments were conducted on the servo-hydraulic MTS 809 testing machine at room temperature, with a constant displacement rate of $0.06 \mathrm{~mm} \cdot \mathrm{min}^{-1}$.

\subsection{Effective elastic modulus}

The mechanical properties used in the model are summarized in Table 1. To compare with the proposed model, The classical methods to predict the effective elastic modulus, such as the Mori-Tanaka scheme, non-interaction approximation and differential scheme, were used to compare with the proposed model, as well as the experimental results.

The effective elastic modulus $E_{1}$ of the CMCs after thermal shocks are expressed in Fig. 6. The solid line in the figure shows the prediction results of the proposed model, the dotted lines are the predicted results of other methods, and the circle is the experimental results. As the porosity increases, the elastic modulus decrease near linearly, implying that the change of porosity controls the material property.

The results also suggest that the errors of the proposed model with the experimental results are smaller than the other models, as the other models may overestimate or underestimate the

Table 1

Mechanical properties of the components in oxide/oxide CMCs (Yang and Yang, 2020; Moser et al., 2001; Moser et al., 2004).

\begin{tabular}{llll}
\hline Parameter & Symbol & Value & Unit \\
\hline Elastic modulus of fiber & $E_{\mathrm{f}}$ & 379 & $\mathrm{GPa}$ \\
Elastic modulus of matrix & $E_{\mathrm{m}}$ & 210 & $\mathrm{GPa}$ \\
Density of fiber & $\rho_{\mathrm{f}}$ & 4.2 & $\mathrm{~g} / \mathrm{cm}^{3}$ \\
Density of matrix & $\rho_{\mathrm{m}}$ & 4.0 & $\mathrm{~g} / \mathrm{cm}^{3}$ \\
Volume fraction of fiber & $V_{\mathrm{f}}$ & 44 & $\%$ \\
Porosity of composite & $\zeta$ & 27.6 & $\%$ \\
Tensile strength of fiber & $T_{\mathrm{f}}$ & 2730 & $\mathrm{MPa}$ \\
Tensile strength of matrix & $T_{\mathrm{m}}$ & $\approx 45$ & $\mathrm{MPa}$ \\
\hline
\end{tabular}

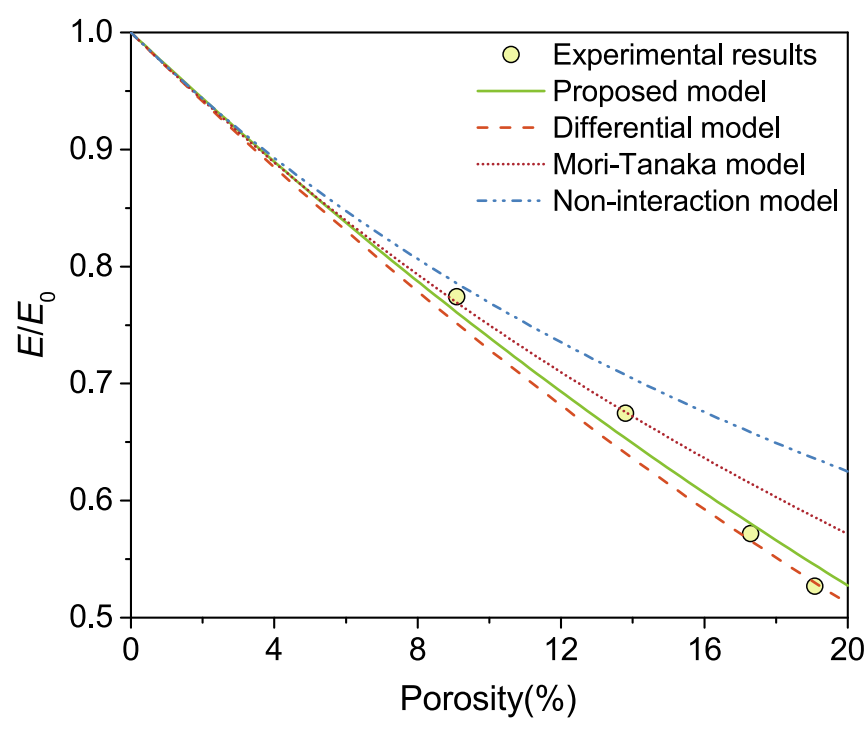

Fig. 6. The effective elastic modulus $E_{1}$ of the CMCs after thermal shocks. The solid lines are the predict results of the proposed model, the dotted lines are the predicted results of other methods, and the circles are the experimental results.

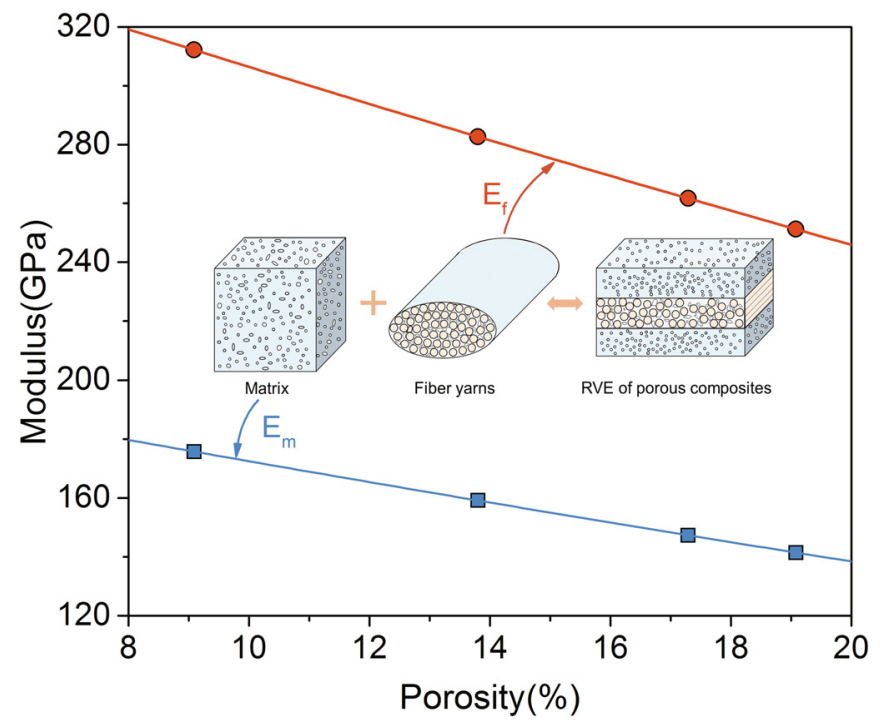

Fig. 7. The predicted modulus of fibers and matrix by the proposed model as function of porosity.

impact of pores, which may due to the hierarchical porosity isn't taken into account when predicting the elastic modulus.

Besides, the fiber and matrix elastic modulus were also predicted by the proposed model, as demonstrated in Fig. 7. The fiber modulus is much higher than the matrix modulus, as the fibers carry more load. Moreover, with the porosity increases, both the fiber modulus and matrix modulus decrease, because that there are micropores in the fiber bundles and matrix, when suffering from thermomechanical loading, the pores will expand and coalesce, leading to the carrying capacity of the material decrease, and the macroscopic performance is the decrease of modulus.

\subsection{Characterization of the matrix damage}

\subsubsection{Identification of the damage model}

The identification of the matrix damage model presented in Eq. (25) needs four material parameters: 


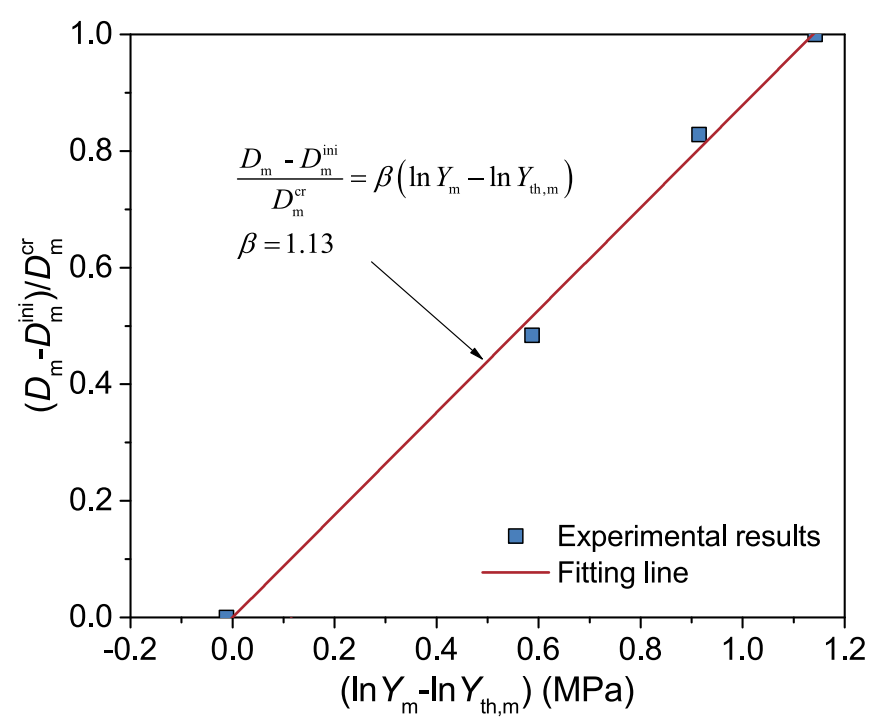

Fig. 8. The identification of damage exponent $\beta$ of matrix damage evolution, where the slope of the best linear fit is the first verification of the damage exponent $\beta$.

(a) The threshold strain energy release rate $Y_{\text {th,m }}$, which indicates the damage process initiation;

(b) The initial matrix damage $D_{\mathrm{m}}^{\mathrm{ini}}$, because damage present in the matrix is evaluated through the decrease of stiffness with respect to the initial elastic modulus, $D_{\mathrm{m}}^{\mathrm{ini}}$ is assumed equal to zero;

(c) The critical matrix damage $D_{\mathrm{m}}^{\mathrm{cr}}$, when the damage reaches $D_{\mathrm{m}}^{\mathrm{cr}}$, the matrix will fail;

(d) The damage parameter $\beta$, determining the shape of the matrix damage evolution.

It should be noted that in the matrix damage model, all parameters have physical meaning and can be determined experimentally and the iterative calculations are not necessary. The identification of the parameters describing the damage model of the matrix is performed by the experimental results measured in a simple uniaxial test.

In fact, the matrix damage as a function of the strain energy density release rate can be obtained using a logarithmic plot $\left(D_{\mathrm{m}}-D_{\mathrm{m}}^{\mathrm{ini}}\right) / D_{\mathrm{m}}^{\mathrm{cr}}$ versus $\left(\ln Y_{\mathrm{m}}-\ln Y_{\mathrm{th}, \mathrm{m}}\right)$, the meaning of the slope of the best linear fit is the first verification of the damage exponent $\beta$, as

$\frac{D_{\mathrm{m}}-D_{\mathrm{m}}^{\mathrm{ini}}}{D_{\mathrm{m}}^{\mathrm{cr}}}=\beta\left(\ln Y_{\mathrm{m}}-\ln Y_{\mathrm{th}, \mathrm{m}}\right)$

Then $\beta$ can be derived from the available data point. Fig. 8 shows the logarithmic plot for the damage exponent $\beta$ estimation, and $\beta$ is obtained as 1.13 for the oxide/oxide CMCs.

\subsubsection{Matrix damage evolution}

Fig. 9 gives the matrix damage evolution in the oxide/oxide CMCs under cyclic thermal shocks, and the experiments have been carried out in the previous work (Yang et al., 2019). The matrix damage is obtained by measuring the porosity in the matrix and calculating the effective elastic modulus of the matrix. The thermomechanical damage starts with the threshold strain energy release rate $Y_{\text {th.m }}$, in correspondence with which microcracks and pores begin to nucleate around the included particles by original pore breaking. With $Y_{\mathrm{m}}$ increases, the new pores are nucleated, while the size of the existing pores basically remains unchanged, and a large number of micropores are formed, leading to the damage accumulates rapidly. Finally, the matrix damage reaches a satura-

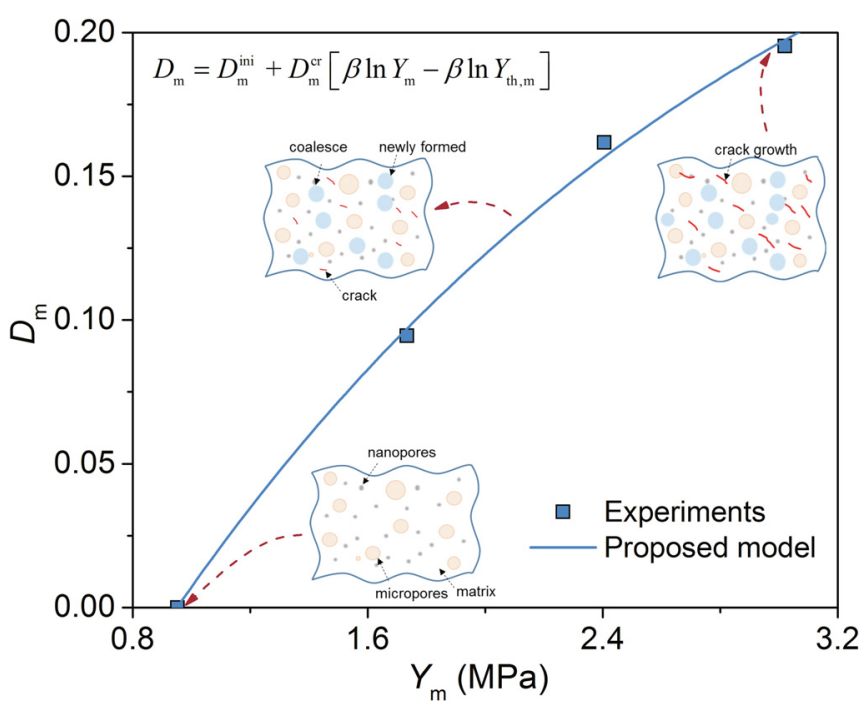

Fig. 9. Matrix damage evolution in the oxide/oxide CMCs under cyclic thermal shocks with the strain energy release rate $Y_{\mathrm{m}}$.

tion stage, where $D_{\mathrm{m}}^{\mathrm{cr}}=0.2$ at $Y_{\mathrm{m}}=3.1 \mathrm{MPa}$ as the crack density no longer increase. With the spacing between pores reduction, further loading increase will cause the sudden coalescence of pores and the final failure of the matrix.

The damage evolution law of the matrix takes into account the overall effects of micropore nucleation, stable growth, and agglomeration, which is a nonlinear damage evolution with the strain energy release rate. Besides, the global effect of the pore growth on the decrease of the matrix property can be accurately described by the four damage parameters mentioned above considering the three stages of the pore growth. The determination of the parameters has been described in the above.

\subsection{Fiber damage characterization}

\subsubsection{Identification of the damage model}

Eq. (31) shows that the fiber damage $D_{\mathrm{f}}$ is a function of the strain $\varepsilon_{\mathrm{f}}$. Furthermore, when the damage $D_{\mathrm{f}}$ gets close to the critical value, $D_{\mathrm{f}}^{\mathrm{cr}}$, the final deformation stage before failure is mainly dominated by the brittle fracture of the fibers, which quickly pushes the net resistance area to instability. Besides, when the strain is less than $\varepsilon_{\mathrm{th}, \mathrm{f}}$, elastic deformation occurs, and the damage amount $D_{\mathrm{f}}=0$. To apply the Eq. (31), the damage and strain threshold should be considered, the evolution equation of fiber damage becomes:

$D_{\mathrm{f}}=D_{\mathrm{f}}^{\mathrm{cr}}\left\{1-\exp \left[-\left(\frac{E_{\mathrm{f}}\left\langle\varepsilon_{\mathrm{f}}-\varepsilon_{\mathrm{th}, \mathrm{f}}\right\rangle}{\sigma_{\mathrm{w}}}\right)^{\alpha}\right]\right\}$

where $\langle\cdot\rangle$ notes the Macauley brackets, i.e. $x \geqslant 0,\langle x\rangle=x ; \alpha$ is the material parameters. Then the fiber damage evolution can be determined by the four parameters: the damage threshold $D_{\mathrm{f}}^{\mathrm{cr}}$, the strain threshold $\varepsilon_{\mathrm{th}, \mathrm{f}}$, the shape parameters $\sigma_{w}$ and $\alpha$.

Experimental data has shown that the fiber bundles damage evolution is a nonlinear process, and the identification of the parameters in the damage evolution law should enable the experimental results and model predictions to be optimal under a variety of load cases such as thermal loads, mechanical loads, and even their coupling.

However, the damage exponent $\alpha$, which carries information for the shape of the damage evolution, can describe the kinetic law of damage evolution as a function of strain $\varepsilon_{\mathrm{f}}$, thus include the global 


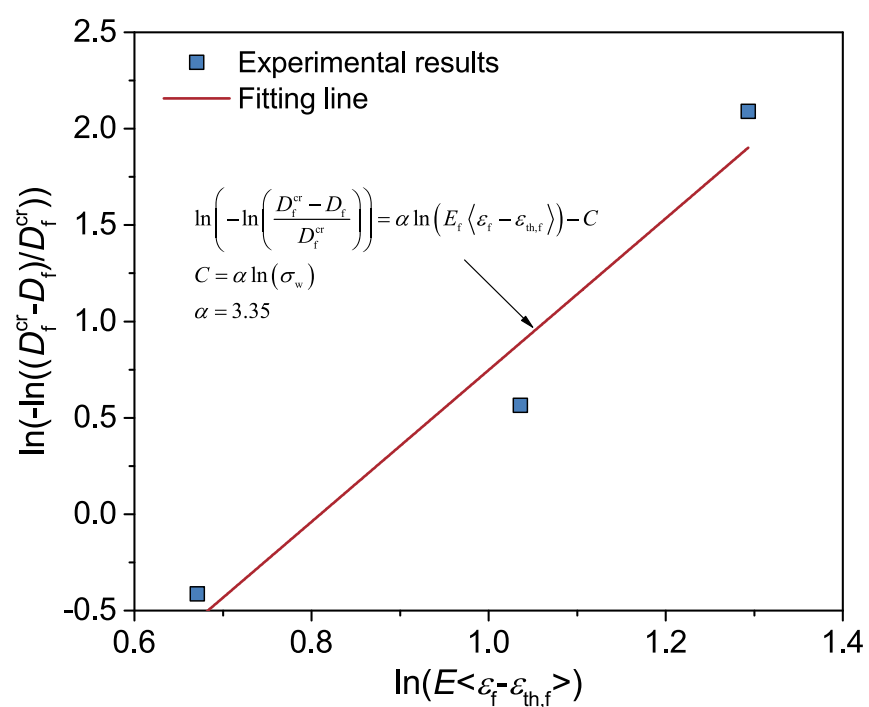

Fig. 10. The exponent $\alpha$ determined as the slope of the best-fit line of the experimental damage measurements.

effects in the proposed nonlinear damage model, and it can be determined by experimental results. The exponent $\alpha$ is determined as the slope of the best-fit line of the experimental damage measurements, as shown in Fig. 10, which is given by

$\ln \left(-\ln \left(\frac{D_{\mathrm{f}}^{\mathrm{cr}}-D_{\mathrm{f}}}{D_{\mathrm{f}}^{\mathrm{cr}}}\right)\right)=\alpha \ln \left(E_{\mathrm{f}}\left\langle\varepsilon_{\mathrm{f}}-\varepsilon_{\mathrm{th}, \mathrm{f}}\right\rangle\right)-C$

with

$C=\alpha \ln \left(\sigma_{\mathrm{w}}\right)$

In the absence of experimental data related to proportionally loading geometry, a failure strain was assumed until a proper fitting of the damage measurement was obtained.

\subsubsection{Fiber damage evolution}

Fiber damage evolution prediction in CMCs has been obtained by Eq. (33) and compared with experimental results, as illustrated in Fig. 11, which shows that the prediction of the model is in good agreement with experimental results. It is evident that these slope

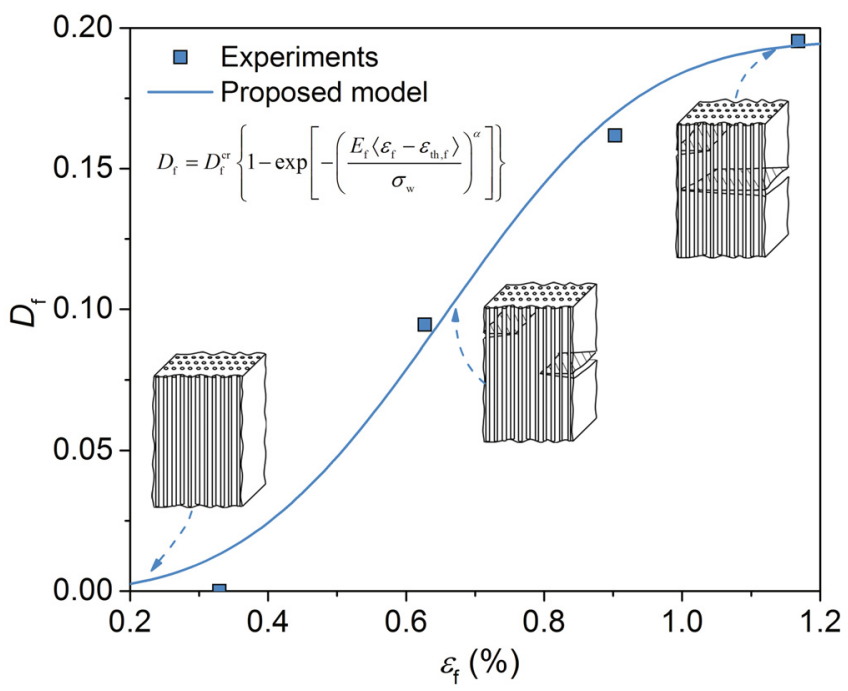

Fig. 11. Fiber damage evolution predictions in CMCs obtained by Eq. (33) are compared with experimental results. The schematic of the fracture behaviors for the fibers is also exhibited. changes are related to damage processes that alter the material microstructure and its global response.

From the point of view strain, three different zones can be identified: For $\varepsilon_{\mathrm{f}}$ from 0 to $0.32 \%$, the fibers are in the elastic range, with no damage in this regime, and the elastic modulus is constant; When strain increases between $0.32 \%$ and $1 \%$, damage starts to take place and accumulates rapidly, as the fibers are brittle for CMCs; As soon as strain higher than $1 \%$, the damage is maintained through the final fracture, which can be explained as: when the critical strain level for one fiber is reached, it fails and the excess stress is redistributed to the remaining fibers. Near the end of the fracture process, the additional strain is absorbed by the opening of the new cracks.

The results have indicated that the fibers in CMCs can exhibit three-stage behavior: (i) The fibers begin to crack as the damage occurs with the strain reaches $\varepsilon_{\text {th,f }}$; (ii) There are multiple cracks exists in the fibers perpendicular to the loading direction, and the already existing cracks extend across the section, leading to the rapid increase of damage; (iii) When the damage reaches the stable stage as the strain increases, there may exhibit a dominant crack, and when the crack extends across the fibers, the fiber failure occurs. The behaviors of the fibers are also sketched in Fig. 11 as a schematic, which is not the actual fracture process of the CMCs, as the CMCs are the woven composites.

\section{Conclusions}

In the present work, the effect of hierarchical porosity on elastic properties of porous woven composites under thermomechanical loading is investigated, and a micro-mechanics based damage model of the porous woven composites containing hierarchical porosity is proposed within the CDM framework to analyze the effect of hierarchical porosity in both the matrix and fibers on elastic properties and damage. Experiments are also performed to verify the correctness of the proposed model. A key distinction from approaches adopted by others is considering the change of the hierarchical porosity of the porous woven composites during loading when predicting the effective elastic property, and thus, the distribution of manufacturing process-induced hierarchical pores throughout the composites could be controlled. The main conclusions can be drawn as follows:

- The concept of 'hierarchical porosity' is introduced to describe nanopores and micropores of rather different sizes in the porous woven composites, which is produced in the manufacturing process and has been verified in the SEM observation. The nanopores can be found in the matrix and the micropores can be observed in the matrix, fibers and interface. More essentially, the change of hierarchical porosity during loading controls the mechanical behavior of materials.

- A micromechanics-based model to determine the effective elastic properties of porous woven composites is proposed, which can interpret the change of effective elastic property of a porous composite as a consequence of its hierarchic porosity, thus enabling to consider hierarchical porous microstructures. The model allows for flexible applications of micromechanical estimation to the microstructures of a large variety of porous woven composites.

- Taking into account stiffness reduction in the matrix and fibers during thermomechanical loading, a CDM-based damage model is proposed to describe the damage evolution in the matrix and fibers. Two damage variables in the micromechanics level are used and the damage evolution law is established based on microscopic damage mechanism for each of the damage variables. 
- The proposed model is applied to the oxide/oxide CMCs as a demonstrative example. A good agreement between the proposed model and experimental results shows the capability of the proposed model in effective property prediction and damage characterization of porous woven composites under thermomechanical loading conditions.

\section{Acknowledgement}

The present work is supported by the Strategic Priority Research Program of Chinese Academy of Sciences (Grant No. XDA17030100), the support by the National Natural Science Foundation of China (No. 11932020, 11872364) and CAS Pioneer Hundred Talents Program. The authors would also like to thank the reviewers for their fruitful discussions and constructive comments.

\section{Appendix A. Supplementary data}

Supplementary data associated with this article can be found, in the online version, athttps://doi.org/10.1016/j.ijsolstr.2020.05.002.

\section{References}

Baghaei, B., Skrifvars, M., Salehi, M., Bashir, T., Rissanen, M., Nousiainen, P., 2014. Novel aligned hemp fibre reinforcement for structural biocomposites: porosity, water absorption, mechanical performances and viscoelastic behaviour. Compos. Part A: Appl. Sci. Manuf. 61, 1-12.

Bale, H.A., Haboub, A., MacDowell, A.A., Nasiatka, J.R., Parkinson, D.Y., Cox, B.N., Marshall, D.B., Ritchie, R.O., 2013. Real-time quantitative imaging of failure events in materials under load at temperatures above 1600 C. Nat. Mater. 12 (1), 40-46.

Chao, X., Qi, L., Tian, W., Hou, X., Ma, W., Li, H., 2018. Numerical evaluation of the influence of porosity on bending properties of 2D carbon/carbon composites. Compos. Part B: Eng. 136, 72-80.

Chateau, C., Gélébart, L., Bornert, M., Crépin, J., 2015. Micromechanical modeling of the elastic behavior of unidirectional CVI SiC/SiC composites. Int. J. Solids Struct. 58, 322-334.

Chateau, C., Gélébart, L., Bornert, M., Crépin, J., Caldemaison, D., Sauder, C., 2014. Modeling of damage in unidirectional ceramic matrix composites and multiscale experimental validation on third generation $\mathrm{SiC} / \mathrm{SiC}$ minicomposites. J. Mech. Phys. Solids 63, 298-319.

Chen, N., Silberstein, M.N., 2019. A micromechanics-based damage model for nonwoven fiber networks. Int. J. Solids Struct. 160, 18-31.

Choi, H.K., Son, M.J., Shin, E.S., Yu, J., 2018. Prediction of thermo-poro-elastic properties of porous composites using an expanded unmixing-mixing model. Compos. Struct. 188, 387-393.

Cicekli, U., Voyiadjis, G.Z., Abu Al-Rub, R.K., 2007. A plasticity and anisotropic damage model for plain concrete. Int. J. Plast. 23 (10), 1874-1900.

Huang, H., Talreja, R., 2005. Effects of void geometry on elastic properties of unidirectional fiber reinforced composites. Compos. Sci. Technol. 65 (13), 19641981.

Larson, N.M., Cuellar, C., Zok, F.W., 2019. X-ray computed tomography of microstructure evolution during matrix impregnation and curing in unidirectional fiber beds. Compos. Part A: Appl. Sci. Manuf. 117, 243-259.
Lemaitre, J., Desmorat, R., 2005. Engineering Damage Mechanics: Ductile, Creep, Fatigue and Brittle Failures. Springer-Verlag, Berlin Heidelberg, Berlin, Heidelberg.

Liang, Z., Lee, H.K., Suaris, W., 2006. Micromechanics-based constitutive modeling for unidirectional laminated composites. Int. J. Solids Struct. 43 (18), 56745689.

Liebig, W.V., Schulte, K., Fiedler, B., 2016. Hierarchical analysis of the degradation of fibre-reinforced polymers under the presence of void imperfections. Philos. Trans. R. Soc. A 374 (2071), 20150279.

Ma, L.-H., Yang, Q.-S., Yan, X.-H., Qin, Q.-H., 2014. Elastoplastic mechanics of porous materials with varied inner pressures. Mech. Mater. 73, 58-75.

Mihai, I.C., Jefferson, A.D., 2017. A micromechanics based constitutive model for fibre reinforced cementitious composites. Int. J. Solids Struct. 110-111, 152169.

Morales-Rodrguez, A., Reynaud, P., Fantozzi, G., Adrien, J., Maire, E., 2009. Porosity analysis of long-fiber-reinforced ceramic matrix composites using X-ray tomography. Scr. Mater. 60 (6), 388-390.

Moser, B., Rossoll, A., Weber, L., Beffort, O., Mortensen, A., 2001. Nextel610 alumina fibre reinforced aluminium: influence of matrix and process on flow stress. Compos. Part A 32 (8), 1067-1075.

Moser, B., Rossoll, A., Weber, L., Beffort, O., Mortensen, A., 2004. Damage evolution of Nextel 610alumina fibre reinforced aluminium. Acta Mater. 52 (3), 573-581.

Nguyen, G.D., Bui, H.H., 2019. A thermodynamics-and mechanism-based framework for constitutive models with evolving thickness of localisation band. Int. J. Solids Struct.

Patel, D.K., Waas, A.M., Yen, C.-F., 2019. Compressive response of hybrid 3D woven textile composites (H3DWTCs): an experimentally validated computational model. J. Mech. Phys. Solids 122, 381-405.

Rajan, V.P., Zok, F.W., 2012. Effects of non-uniform strains on tensile fracture of fiber-reinforced ceramic composites. J. Mech. Phys. Solids 60 (12), 2003-2018.

Rajan, V.P., Zok, F.W., 2014. Matrix cracking of fiber-reinforced ceramic composites in shear. J. Mech. Phys. Solids 73, 3-21.

Sevostianov, I.K.V., 2009. Effect of pore distribution on the statistics of peak stress and overall properties of porous material. Int. J. Solids Struct. 46 (25-26), 44194429.

Sun, X.-Y., Xu, G.-K., Li, X., Feng, X.-Q., Gao, H., 2013. Mechanical properties and scaling laws of nanoporous gold. J. Appl. Phys. 113, (2) 023505.

Timothy, J.J., Meschke, G., 2016. A cascade continuum micromechanics model for the effective elastic properties of porous materials. Int. J. Solids Struct. 83, 1-12.

Tretiak, I., Smith, R.A., 2019. A parametric study of segmentation thresholds for Xray CT porosity characterisation in composite materials. Compos. Part A 123, $10-24$.

Vincent, P.-G., Monerie, Y., Suquet, P., 2009. Porous materials with two populations of voids under internal pressure: I. Instantaneous constitutive relations. Int. J. Solids Struct. 46 (3), 480-506.

Vural, M., Ravichandran, G., 2003. Microstructural aspects and modeling of failure in naturally occurring porous composites. Mech. Mater. 35, 523-536.

Xia, R., Feng, X.-Q., Wang, G.-F., 2011. Effective elastic properties of nanoporous materials with hierarchical structure. Acta Mater. 59 (17), 6801-6808.

Xia, R., Xu, C., Wu, W., Li, X., Feng, X.-Q., Ding, Y., 2009. Microtensile tests of mechanical properties of nanoporous au thin films. J. Mater. Sci. 44 (17), 4728 4733.

Yang, Z., Liu, H., 2020. An elastic-plastic constitutive model for thermal shocked oxide/oxide ceramic-matrix composites. Int. J. Mech. Sci. 105528. https://doi. org/10.1016/j.ijmecsci.2020.105528.

Yang, Z., Liu, H., Yuan, H., 2019. Micro-porosity as damage indicator for characterizing cyclic thermal shock-induced anisotropic damage in oxide/ oxide ceramic matrix composites. Eng. Fract. Mech. 220, 106669, https://doi. org/10.1016/j.engfracmech.2019.106669.

Yang, Z., Yang, J., 2020. Investigation of long-term thermal aging-induced damage in oxide/oxide ceramic matrix composites. J. Eur. Ceram. Soc. 40 (4), 1549-1556. 